\title{
Macroeconomics After the Great Recession, II
}

\author{
Emine Boz ${ }^{1} \cdot$ Linda Tesar ${ }^{2}$
}

(C) International Monetary Fund 2018

The 17th Jacques Polak Annual Research Conference on Macroeconomics, held at the IMF in Washington on November 3-4, 2016, was organized around the theme of "Macroeconomics after the Great Recession" and celebrated Olivier Blanchard's contributions to macroeconomics and the Fund. The first set of conference papers appeared in the previous issue. Below we summarize the key contributions of the papers that appear in the current issue, the second and last of the issues based on this conference.

The 2016 Mundell-Fleming lecture was delivered by Larry Summers, Olivier's long-time friend, colleague and co-author. In his remarks, Larry revisits the problem of secular stagnation - protracted low aggregate demand in the face of low-interest rates. Larry first articulated the concept of secular stagnation in the fall of 2013 on the same stage as a policy panelist at our 14th Annual Research Conference. ${ }^{1}$ Larry argues that the case for secular stagnation has only strengthened over time as the events since 2013 have tended to confirm its predictions and reject those of its critics. Acknowledging that this theory is far from providing a complete explanation of what has happened in the industrial world in recent years, he argues nonetheless that it offers important insights and requires a rethinking of macroeconomic policy. Larry concludes by outlining the theory's implications for monetary and fiscal policies.

\footnotetext{
${ }^{1}$ Given the lively debate that ensued, his original remarks were published in the IMF Economic Review. See Summers (2015).
}

Emine Boz

EBoz@imf.org

Linda Tesar

ltesar@umich.edu

1 International Monetary Fund (IMF), Washington, DC, USA

2 University of Michigan, Ann Arbor, USA 
The second paper in this issue focuses on the interplay between monetary policy and the incentives of the financial sector ["Moral Hazard Misconceptions: the Case of the Greenspan Put" by Gideon Bornstein (Northwestern University) and Guido Lorenzoni (Northwestern University)]. A frequently articulated position - the so-called Greenspan put - is that the adjustment of interest rates ex post to achieve macroeconomic stability creates moral hazard on the part of borrowers ex ante. By supporting asset prices in the event of a crisis, policymakers create incentives for excessive borrowing. In so doing, countercyclical interest rate policy may end up increasing, rather than reducing, macroeconomic volatility. In this paper, the authors shift the policy externality from asset prices to real output. They find that monetary policy that aims to reduce the output gap also reduces the externalities associated with ex ante financial decisions, eliminating the conflict between macroprudential and stabilization policy objectives.

The third paper examines ECB interventions in the market for Greek bonds during the 2010 crisis period. ["ECB Interventions in Distressed Sovereign Debt Markets: The Case of Greek Bonds" by Christoph Trebesch (Kiel Institute for the World Economy and CEPR) and Jeromin Zettelmeyer (Peterson Institute for International Economics and CEPR)]. This episode provides a unique environment to study the efficacy of central bank interventions in asset markets. The paper finds that ECB bond buying had a large impact on the price of short- and medium-maturity Greek bonds. However, the effects were contained to those sovereign bonds actually purchased by the ECB and did not spillover to close substitute bonds, CDS markets, or corporate bonds.

"Managing Capital Outflows with Limited Reserves" by Suman Basu (IMF), Atish Ghosh (IMF), Jonathan Ostry (IMF) and Pablo Winant (Bank of England), turns to a problem faced by many central banks in emerging markets: what is the optimal intervention policy to stabilize the exchange rate when reserves are limited and capital is mobile? The paper shows that the optimal policy depends on the persistence of the shock to outflows and the credibility of the central bank. A central bank with full commitment achieves a gradual depreciation to the purefloat level by promising sustained future intervention, such that reserves are exhausted after particularly adverse shocks. A central bank without commitment intervenes little, wishing to preserve some reserves forever, and suffers a larger immediate exchange rate depreciation and associated welfare cost.

The last paper in this issue takes up a key question facing fiscal policy during the global financial crisis. "On the Optimal Speed of Sovereign Deleveraging with Precautionary Savings" by Thomas Philippon (NYU Stern School of Business) and Francisco Roldán (New York University) highlights the trade-off between the contractionary effects of fiscal consolidation today and the benefits of reducing the risk of a sovereign debt crisis in the future. When the risk of default is very responsive to the level of debt, their model predicts that austerity can be expansionary. This is because an increase in taxes can lead to a decrease in precautionary savings that is strong enough to offset the direct effect on the disposable income of constrained agents. Additionally, they find that savers and borrowers disagree about the optimal path of sovereign deleveraging, and relate this insight to the rise in political disagreement about fiscal policy. 
We hope that you enjoy this issue and we again extend our thanks to Olivier for his many contributions and, in particular, for establishing the IMF Economic Review.

\section{Reference}

Summers, Lawrence H. 2015. Have we entered an age of secular stagnation? IMF Economic Review 63(1): 277-280. 